\title{
Inferior Petrosal Sinus Sampling in Healthy Human Subjects Reveals a Unilateral Corticotropin-releasing Hormone-induced Arginine Vasopressin Release Associated with Ipsilateral Adrenocorticotropin Secretion
}

\author{
Konstantine T. Kalogeras, ${ }^{\star \ddagger \Uparrow \neq \ddagger ~ L y n n e t t e ~ K . ~ N i e m a n, ~}{ }^{\ddagger}$ Theodore C. Friedman, ${ }^{\ddagger \star \star}$ John L. Doppman, ${ }^{\S}$ Gordon B. Cutler, Jr., ${ }^{\ddagger}$

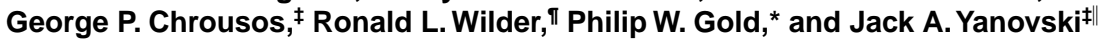 \\ * Clinical Neuroendocrinology Branch, National Institute of Mental Health, ${ }^{\star}$ Developmental Endocrinology Branch, National Institute of \\ Child Health and Human Development, ${ }^{\S}$ Diagnostic Radiology Department, and ${ }^{\|}$Office of the Director, Warren Grant Magnuson \\ Clinical Center, and "Arthritis and Rheumatism Branch, National Institute of Arthritis and Musculoskeletal and Skin Diseases, National \\ Institutes of Health, Bethesda, Maryland 20892; **Department of Medicine, Cedars-Sinai Medical Center, University of California School \\ of Medicine, Los Angeles, California 90048; and ${ }^{\ddagger}$ Department of Psychiatry and Human Behavior, The University of Mississippi Medical \\ Center, School of Medicine, Jackson, Mississippi 39216
}

\begin{abstract}
Arginine vasopressin (AVP) acts synergistically with corticotropin-releasing hormone (CRH) to stimulate ACTH release from the anterior pituitary. In a previous study of bilateral simultaneous inferior petrosal sinus (IPS) sampling in healthy human subjects, we observed lateralized ACTH secretion, suggesting lateralized secretion of an ACTH-regulating hypothalamic factor. To investigate this possibility, we measured ACTH, CRH, AVP, and oxytocin (OT) levels in the IPS and the peripheral circulation in nine normal volunteers, before and after $1 \mu \mathrm{g} / \mathrm{kg}$ i.v. bolus ovine CRH (oCRH). At baseline, ACTH, AVP, and OT exhibited a significant $(P<0.05)$ two to threefold intersinus gradient (ISG), indicating the existence of a dominant petrosal sinus. Endogenous CRH was undetectable in all samples. Despite similar exogenous oCRH levels in both petrosal sinuses, oCRH caused a significant increase $(P<0.001)$ in the ACTH ISG (15.8 \pm 5.6 , mean \pm SEM), suggesting increased responsiveness of one dominant side of the anterior pituitary. This was associated with an ipsilateral CRH-induced AVP release and a significant increase $(P<0.01)$ in the AVP ISG (8.6 \pm 2.3 ), suggesting lateralized AVP secretion by the hypothalamus. Furthermore, the increased AVP ISG after oCRH correlated strongly with the ACTH ISG ( $r=$ $0.92, P<0.01$ ). oCRH administration did not affect OT. These findings suggest that there is a dominant petrosal sinus in healthy volunteers that appears to reflect a dominant side of the adenohypophysis, characterized by increased functional activity and/or responsiveness of the pituitary corticotrophs. This may reflect lateralized hypothalamic and/ or suprahypothalamic function resulting in CRH-responsive lateralized secretion of AVP from parvocellular and/or magnocellular axons in the median eminence and the posterior pituitary. Although the functional and teleologic signif-
\end{abstract}

Part of this work was presented at the First World Congress on Stress, Bethesda, MD, 4-7 October, 1994.

Address correspondence to Konstantine T. Kalogeras, M.D., Laboratory of Clinical Neuroendocrinology, Department of Psychiatry and Human Behavior, The University of Mississippi Medical Center, School of Medicine, Jackson, MS 39216-4505. Phone: 601-9845898; FAX: 601-984-5899; E-mail:kalogera@fiona.umsmed.edu

Received for publication 21 July 1995 and accepted in revised form 8 February 1996.

The Journal of Clinical Investigation

Volume 97, Number 9, May 1996, 2045-2050 icance of these findings remains to be investigated, our data suggest a novel mechanism for CRH-mediated ACTH release, namely CRH-induced release of AVP which then enhances CRH action on the corticotrophs. Furthermore, our data represent the first direct evidence for the concept of brain lateralization with respect to neuroendocrine secretion. (J. Clin. Invest. 1996. 97:2045-2050.) Key words: hypothalamus • median eminence $\bullet$ adenohypophysis $\bullet$ neurohypophysis • oxytocin

\section{Introduction}

The capacity for assessment of human anterior pituitary secretory activity has been enhanced by the development of inferior petrosal sinus (IPS) ${ }^{1}$ sampling. Blood from the venous plexus that drains the anterior and posterior pituitary empties into the right and left cavernous sinuses, which connect to the jugular veins via the inferior petrosal sinuses. Sampling of IPS blood thus provides a unique opportunity for assessment of pituitary secretion, before dilution by the systemic circulation. Simultaneous bilateral IPS sampling has been applied extensively for the differential diagnosis of patients with Cushing syndrome (1-3). In a recent report, Yanovski et al. found ACTH to be secreted in a lateralized fashion in the IPS of six healthy human subjects, resulting in the inability of IPS sampling to distinguish Cushing disease from normal physiology (4). Lateralized ACTH secretion in the IPS of patients with Cushing disease is a common finding, with increased ACTH secretion into the IPS ipsilateral to the tumor in $\sim 70 \%$ of the patients. However, lateralized ACTH secretion in normal subjects was an unexpected finding that suggested differences in the functional activity of the corticotrophs in the two sides of the anterior pituitary gland. Such differences could possibly be due to differential stimulation by lateralized secretion of ACTH-regulating hypothalamic factor(s).

The secretion of ACTH by the anterior pituitary is regulated by two major hypothalamic secretagogues, corticotropinreleasing hormone (CRH) (5) and arginine vasopressin (AVP), which exerts a strong synergistic effect with $\mathrm{CRH}$ at the pituitary corticotroph (6-8). Both CRH and AVP are released into the long portal vessels by axons originating in the parvocellular

1. Abbreviations used in this paper: AVP, arginine vasopressin; $\mathrm{CRH}$, corticotropin-releasing hormone; hCRH, human CRH; IPS, inferior petrosal sinus; ISG, intersinus gradient; ME, median eminence; oCRH, ovine CRH; OT, oxytocin. 
division of the paraventricular nucleus of the hypothalamus and terminating in the external zone of the median eminence. In the nonstressed state, approximately half of parvocellular CRH-producing neurons coexpress AVP (9), while a small number coexpress oxytocin (OT) as well (10). The majority of peripherally circulating AVP originates, together with OT, from magnocellular neurons in the paraventricular nucleus and the supraoptic nucleus of the hypothalamus that terminate in the posterior pituitary. However, while passing through the median eminence and the hypophyseal stalk, magnocellular axons can also release AVP into the long portal system (11, 12). Furthermore, a number of neuroanatomical studies have shown the existence of short portal vessels that allow communication between the posterior and anterior pituitary (12-14). Thus, in addition to parvocellular AVP, magnocellular AVP may influence anterior pituitary ACTH secretion.

While the role of AVP in the regulation of ACTH secretion is well established, the role of OT is somewhat controversial. In the rat, OT, like AVP, exerts a strong synergistic effect with $\mathrm{CRH}$ to increase $\mathrm{ACTH}(7,15)$. By contrast, in humans, endogenous OT induced by breast stimulation decreases plasma ACTH and cortisol $(16,17)$. Exogenously administered OT also appears to have a weak inhibitory effect as indicated by a number of human studies (18-21), however, such an effect has not always been found $(22,23)$.

In addition to the well established synergistic effects of CRH and AVP on the release of ACTH (6-8), CRH administration at a nonhypotensive dose has been shown to stimulate plasma AVP (24-26) and OT (27) in animals, but not in humans (28-30). Recently, Nussey et al. reported lateralized AVP and OT secretion into the IPS of patients with Cushing disease after administration of $\mathrm{CRH}$, without a concomitant change in peripheral AVP or OT levels (31). However, this finding could have been caused by the presence of the pituitary adenoma and might not have represented normal physiology.

Therefore, we investigated the possibility of lateralized secretion of $\mathrm{CRH}, \mathrm{AVP}$, and OT, the three main hypothalamic regulators of $\mathrm{ACTH}$, into the inferior petrosal sinuses of nine healthy human subjects. Since the observed lateralized ACTH secretion in healthy humans was even more prominent after $\mathrm{CRH}$ administration, and since $\mathrm{CRH}$ appears to stimulate AVP and OT, we also evaluated possible AVP and OT responses to exogenous ovine $\mathrm{CRH}$ (oCRH).

\section{Methods}

Subjects. Nine normal volunteers (one female and eight males; age $32.2 \pm 4.0 \mathrm{yr}$, mean $\pm \mathrm{SD}$, range $26-37 \mathrm{yr}$ ) were enrolled in the study. Data from IPS sampling for ACTH from six of the nine subjects were included in our previous report (4). All subjects had normal urine free cortisol excretion $(<248 \mathrm{nmol} / \mathrm{d})$; normal hepatic, renal, and thyroid function; and no history of affective disorder (normal Beck Depression Inventory scores) or other psychiatric illnesses. Subjects were medication free for at least $6 \mathrm{wk}$ before the study. The protocol for IPS sampling with oCRH administration in normal volunteers was approved by the NICHD Investigational Review Board and the NIH Radiation Safety Committee. Informed consent was obtained from all subjects.

Inferior petrosal sinus sampling. Catheterization and sampling of the inferior petrosal sinuses was performed as previously described (32). Briefly, after sedation with intravenous diazepam (1-2 mg) and fentanyl $(50-100 \mu \mathrm{g})$, and systemic anticoagulation with heparin
(3,000-4,000 IU), catheters were inserted into the femoral vein and advanced to the petrosal sinuses under fluoroscopic guidance. Blood samples $(10 \mathrm{ml}$ each) were obtained between 0900 and 1100 , simultaneously from each petrosal sinus and a peripheral vein 5 and 1 min before and 3,5, and $10 \mathrm{~min}$ after the intravenous injection of oCRH $(1 \mu \mathrm{g} / \mathrm{kg})$. All samples were collected in prechilled EDTA tubes and were kept on ice until centrifugation (within $2 \mathrm{~h}$ ). The plasma was separated, aliquoted, and frozen at $-20^{\circ} \mathrm{C}$ for ACTH, CRH, AVP, $\mathrm{OT}$, and oCRH determinations. At the conclusion of the sampling, retrograde venography was performed to verify proper catheter placement.

Radioimmunoassays. For measurement of plasma AVP and OT levels, frozen plasma samples $(2.0 \mathrm{ml}$ each $)$ were thawed on ice and acidified with $10 \mathrm{ml}$ of $0.1 \mathrm{~N} \mathrm{HCl}$. The acidified plasma samples were centrifuged and applied to Sep-Pak $\mathrm{C}_{18}$ cartridges (Waters Associates, Millipore Corp., Milford, MA), which had been activated with $10 \mathrm{ml}$ of acetonitrile $\left(\mathrm{CH}_{3} \mathrm{CN}\right)$ followed by $10 \mathrm{ml}$ of $0.1 \mathrm{~N} \mathrm{HCl}$. The cartridges were then washed with $10 \mathrm{ml}$ of $0.1 \%$ trifluoroacetic acid (TFA) and $3 \mathrm{ml}$ of $10 \% \mathrm{CH}_{3} \mathrm{CN}$ in $0.1 \%$ TFA. The absorbed peptides were eluted with $4 \mathrm{ml}$ of $80 \% \mathrm{CH}_{3} \mathrm{CN}$ in $0.1 \%$ TFA. The eluant was collected, and the solvent was removed by means of a speed vacuum concentrator (Savant Instruments, Inc., Farmingdale, NY).

The samples were reconstituted in $0.6 \mathrm{ml}$ of assay buffer, consisting of $10 \mathrm{mM}$ monobasic and $81 \mathrm{mM}$ dibasic sodium phosphate, $\mathrm{pH}$ 7.4, $0.05 \mathrm{M} \mathrm{NaCl}, 0.01 \% \mathrm{NaN}_{3}, 0.1 \% \mathrm{BSA}$, and $0.1 \%$ Triton $\mathrm{X}-100$, and were allowed to dissolve overnight at $4^{\circ} \mathrm{C}$. The RIA was performed in polystyrene tubes by mixing $100 \mu \mathrm{l}$ of sample in duplicate (or standard in triplicate) and $100 \mu \mathrm{l}$ of antiserum. $\left(\mathrm{Arg}^{8}\right)$-vasopressin and OT standards were purchased from Peninsula Laboratories (Belmont, CA). Anti-AVP rabbit serum was obtained from Arnel Corp. (New York, NY), and OT antiserum (R-421) was kindly provided by Dr. Delbert A. Fisher (Torrance, CA). The antiserum titers were 1:90,000 and 1:27,000 for AVP and OT, respectively.

After incubation for $48 \mathrm{~h}$ at $4^{\circ} \mathrm{C}, 100 \mu \mathrm{l}$ of ${ }^{125} \mathrm{I}$-labeled AVP or OT (3,000 cpm) (both from Amersham Corp., Arlington Heights, IL) was added to each tube, and the incubation continued for another $48 \mathrm{~h}$ at $4^{\circ} \mathrm{C}$. Bound and free fractions were then separated by adding $100 \mu \mathrm{l}$ of goat anti-rabbit IgG serum and $100 \mu \mathrm{l}$ of normal rabbit serum (Peninsula Laboratories). The precipitates were allowed to form overnight at $4^{\circ} \mathrm{C}$, then $0.5 \mathrm{ml}$ of assay buffer was added. The precipitate was collected by centrifugation at $1,700 \mathrm{~g}$ for $20 \mathrm{~min}$, and the supernatant was removed by aspiration. The tubes were counted for ${ }^{125} \mathrm{I}$ in a scintillation well gamma counter.

Extraction recovery of AVP and OT added to silica-stripped plasma was $>85 \%$. The standard curve concentration range was 0.36-92.2 pmol/liter for AVP and 1.0-248.2 pmol/liter for OT. The lower limit of detection for the AVP and OT assays was 0.53 and 1.2 $\mathrm{pmol} /$ liter, respectively. The half-maximal displacement of the tracer was $6.8 \mathrm{pmol} /$ liter (AVP) and $16.2 \mathrm{pmol} / \mathrm{liter}(\mathrm{OT})$. The intra- and interassay coefficients of variation of the AVP assay were 5.3 and $7.9 \%$ at $2.9 \mathrm{pmol} / \mathrm{liter}, 4.8$ and $10.7 \%$ at $5.8 \mathrm{pmol} / \mathrm{liter}$, and 6.1 and $9.6 \%$ at $11.5 \mathrm{pmol} /$ liter, respectively. The intra- and interassay coefficients of variation of the OT assay were 4.8 and $4.4 \%$ at $7.8 \mathrm{pmol} / \mathrm{liter}, 2.6$ and $8.4 \%$ at $15.5 \mathrm{pmol} / \mathrm{liter}$, and 3.9 and $7.1 \%$ at $31.0 \mathrm{pmol} / \mathrm{liter}$, respectively.

Plasma ACTH (33), human CRH (hCRH) (34), and oCRH (33) levels were measured by RIA after extraction as previously described. The lower limit of detection for the ACTH, hCRH, and oCRH assays was $0.7,1.8$, and $2.1 \mathrm{pmol} /$ liter, respectively. The mean intra- and interassay coefficients of variation for the ACTH assay were 3.8 and $7.2 \%$, for the hCRH assay 7.0 and $9.7 \%$, and for the oCRH assay 6.2 and $8.2 \%$, respectively. None of the antibodies used for the above determinations exhibited any significant cross-reactivity with related peptide hormones (all $<1 \%$, data not shown), except the hCRH-antibody, which showed significant cross-reactivity with oCRH $(10 \%)$. For this reason, hCRH concentrations were only determined in the -5 and 0 min baseline samples. All samples from the same subject were analyzed in one assay. 
Statistical analysis. All results were expressed as the mean \pm SEM. One and two factor repeated measures ANOVA was performed using Superanova and Statview 4.02 (Abacus Concepts, Berkeley, CA). Due to heteroscedasticity of variance, all values were subjected to logarithmic transformation before the analysis of variance. In some samples, the OT levels and more rarely the AVP levels in the nondominant IPS and the peripheral vein were below the detection limit of the assay. In such case the value of the detection limit was used for all statistical analyses. Fisher paired least significant difference tests were used for multiple comparisons. The dominant inferior petrosal sinus was defined as the sinus with the highest ACTH concentration at $3 \mathrm{~min}$ after oCRH. The intersinus gradient (ISG) was determined at the different time points for each subject, as the ratio of the dominant to nondominant IPS hormone concentrations. The relation between the AVP and ACTH ISG was determined using linear regression.

\section{Results}

Plasma ACTH. As previously reported (4), each subject consistently exhibited a much greater ACTH response to oCRH in one petrosal sinus, which was, therefore, termed the dominant petrosal sinus. Two-way ANOVA with repeated measures demonstrated a significant interaction of time before and after oCRH administration $(-5,0,3,5$, or $10 \mathrm{~min})$ and source of blood (dominant, nondominant petrosal sinus or peripheral vein $)$ for $\operatorname{ACTH}(\mathrm{F}=31.2, \mathrm{df}=8, P<0.001)$. Baseline plasma ACTH was significantly higher in the dominant petrosal sinus $(P<0.05)$ as compared to the periphery. After the administration of oCRH, plasma ACTH was significantly higher at all time points in the dominant IPS $(P<0.001)$ as compared to the nondominant IPS and the peripheral vein (Fig. $1 A$ ).

The ACTH intersinus gradient (ISG) also increased significantly after oCRH administration $(\mathrm{F}=5.4$, df $=4, P<0.001)$, at all time points (Fig. 2). The ACTH ISG increased from $2.2 \pm 0.7$ at $0 \mathrm{~min}$ to a peak value of $15.8 \pm 5.6$ at $5 \mathrm{~min}$ after oCRH. In seven of the nine subjects studied (all of whom were right-handed), the right petrosal sinus was dominant. The probability that the observed predominance of lateralization to the right petrosal sinus was due to chance was calculated from the binomial distribution to be 0.070 .

Plasma AVP. Two-way ANOVA demonstrated a significant interaction of time before and after oCRH and source of blood for AVP $(\mathrm{F}=3.5$, df $=8, P<0.003)$. Baseline plasma AVP was significantly higher in the dominant IPS as compared either to the nondominant IPS $(P<0.05)$ or the periphery $(P<$ 0.01). Plasma AVP increased significantly after oCRH only in the dominant IPS $(\mathrm{F}=3.7$, df $=4, P<0.02)$, but not in the nondominant IPS or the periphery (Fig. $1 B$ ). CRH-induced AVP in the dominant IPS was significantly higher $(P<0.01)$ as compared to the nondominant IPS and the periphery at all time points. The unilateral increase in AVP resulted in a significant increase of the AVP ISG $(\mathrm{F}=4.0, \mathrm{df}=4, P<0.01)$, from a baseline value of $3.0 \pm 0.6$ at $0 \mathrm{~min}$ to a peak value of $8.6 \pm 2.3$ at $10 \mathrm{~min}$ after oCRH (Fig. 2).

Plasma OT. Two-way repeated measures ANOVA demonstrated a significant interaction of the source of blood for OT $(\mathrm{F}=7.6, \mathrm{df}=2, P<0.005)$, but no interaction of time before and after oCRH. Plasma OT concentrations were significantly higher in the dominant IPS $(P<0.05)$ as compared to the nondominant IPS and the periphery at all time points (Fig. $1 C$ ). OT levels were clearly detectable in all samples obtained from the dominant IPS, while they were below the detection

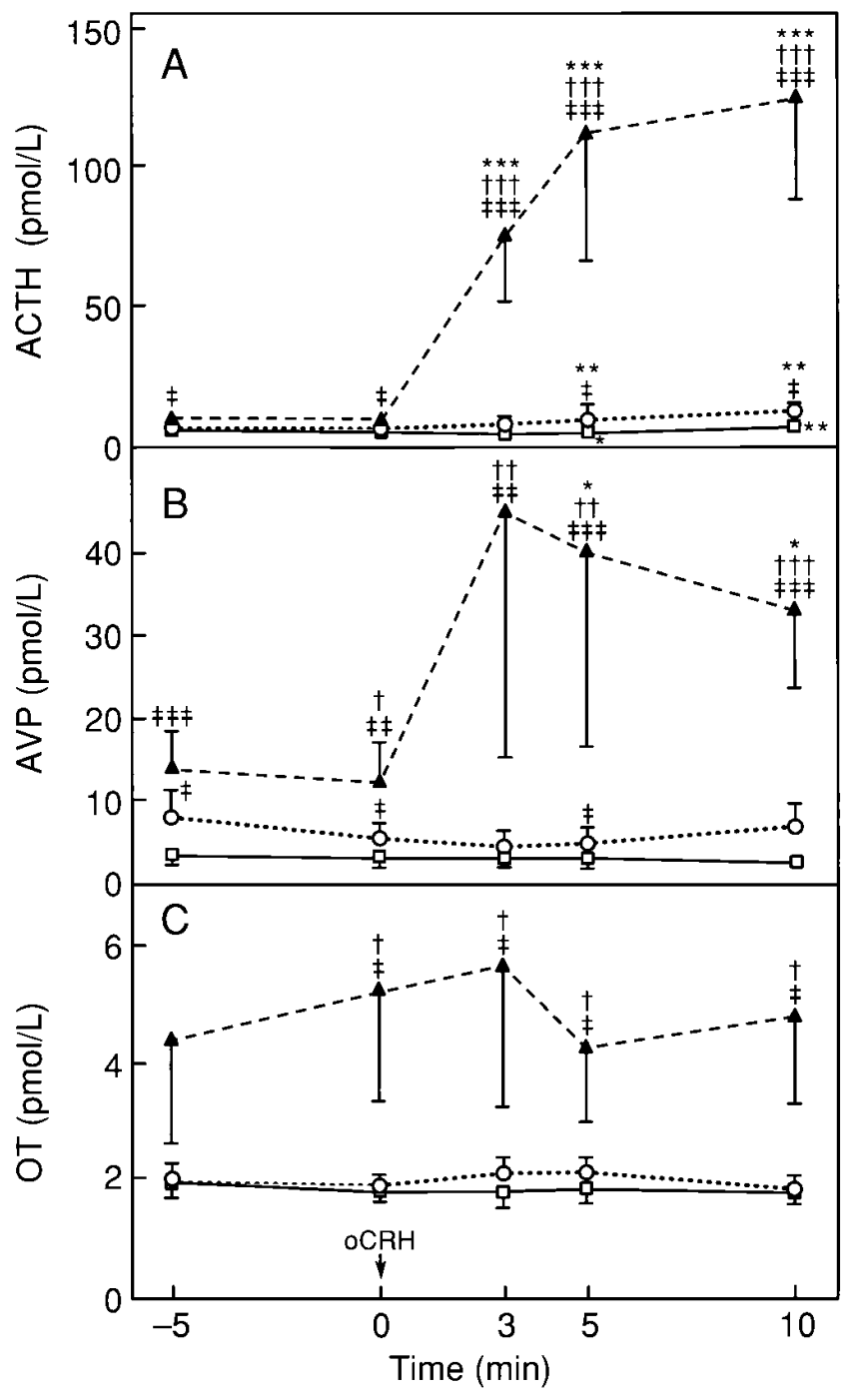

Figure 1. Concurrent plasma concentrations (mean \pm SEM) of ACTH $(A), \operatorname{AVP}(B)$, and OT $(C)$ in the dominant petrosal sinus $(\Delta)$ (defined as the petrosal sinus with the highest ACTH level 3 min after oCRH administration), the nondominant petrosal sinus $(O)$, and a peripheral vein $(\square)$ in nine healthy human subjects. Concentrations at the basal state ( -5 and $0 \mathrm{~min}$ ) and in response to intravenous administration of $1 \mu \mathrm{g} / \mathrm{kg}$ oCRH $(3,5$, and $10 \mathrm{~min})$ are depicted. $* P<$ 0.05 , $* * P<0.01, * * * P<0.001$; compared to baseline concentrations. ${ }^{\dagger} P<0.05,{ }^{\dagger \dagger} P<0.01,{ }^{\dagger \dagger \dagger} P<0.001$; compared to the nondominant petrosal sinus. ${ }^{\ddagger} P<0.05,{ }^{\ddagger} P<0.01,{ }^{{ }^{\ddagger}} P<0.001$; compared to the peripheral vein.

limit of the assay in some samples from the nondominant IPS and the peripheral vein. Neither plasma OT nor OT ISG changed after oCRH administration (Fig. 2).

Plasma hCRH. Endogenous plasma CRH concentrations in the IPS and the periphery were below the detection limit of the assay $(<1.8 \mathrm{pmol} / \mathrm{liter})$ in all subjects (data not shown).

Plasma oCRH levels. Plasma oCRH levels were similar in the two petrosal sinuses at all time points. oCRH levels in the dominant versus nondominant petrosal sinuses reached a peak of $2.3 \pm 0.3$ vs. $2.6 \pm 0.3 \mathrm{nmol} /$ liter at $3 \mathrm{~min}$, and gradually declined to $1.3 \pm 0.1$ vs. $1.3 \pm 0.2 \mathrm{nmol} /$ liter $10 \mathrm{~min}$ after the administration of oCRH (data not shown). 


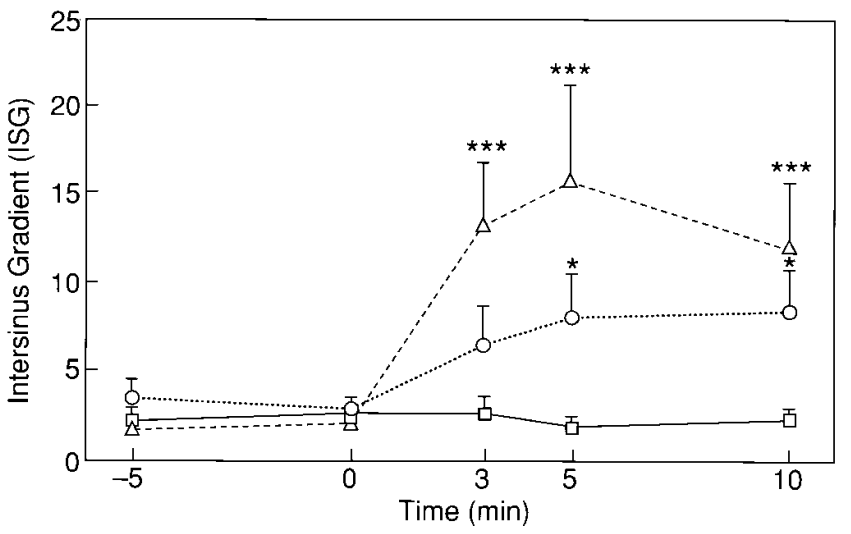

Figure 2. Intersinus Gradient (ISG) (mean \pm SEM) of plasma ACTH $(\triangle)$, AVP $(\bigcirc)$, and OT $(\square)$ concentrations before ( -5 and $0 \mathrm{~min})$ and after $(3,5$, and $10 \mathrm{~min})$ intravenous administration of $1 \mu \mathrm{g} / \mathrm{kg}$ oCRH. $* P<0.05, * * * P<0.001$ - compared to baseline ISG.

Correlation between AVP and ACTH intersinus gradients. No statistically significant correlations were found between the AVP and ACTH ISG at -5 or 0 min (Fig. $3 A$ ). However, after the administration of oCRH, highly significant positive correlations were found between the AVP and ACTH ISG (Fig. 3 $B)$. The correlation coefficient $(r)$ was 0.08 and -0.11 at -5 and $0 \mathrm{~min}$ before, and $0.67(P<0.05), 0.63(P<0.05)$ and 0.92 $(P<0.01)$ at 3,5 , and $10 \mathrm{~min}$ after the administration of oCRH, respectively.

\section{Discussion}

Our data from simultaneous bilateral inferior petrosal sinus sampling demonstrate a single dominant petrosal sinus in healthy human subjects with respect to basal and oCRH-stim-
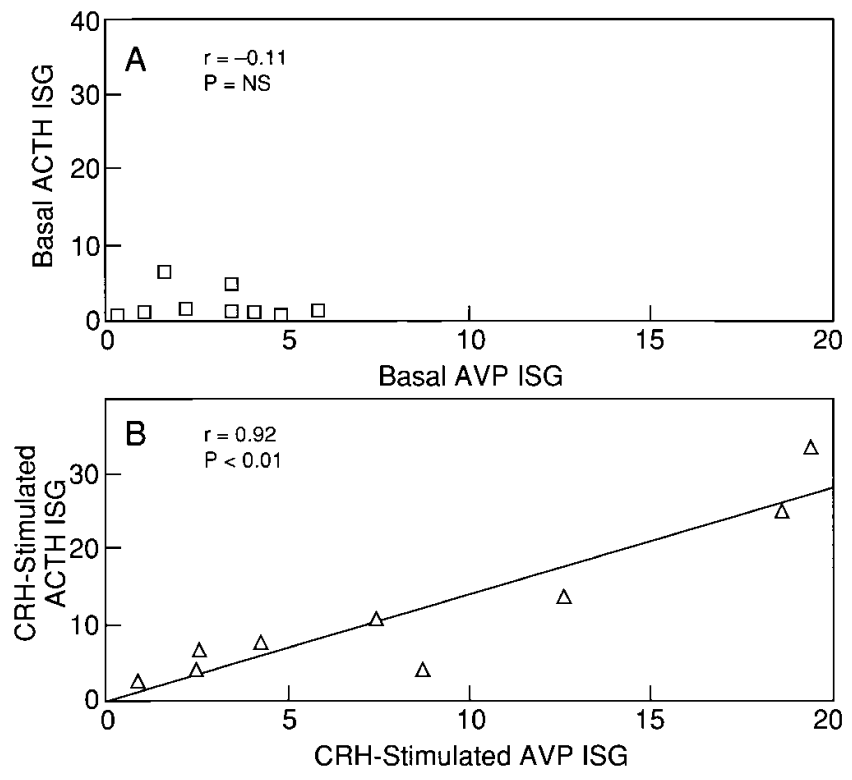

Figure 3. Correlation between basal AVP and ACTH intersinus gradients (ISG) at $0 \mathrm{~min}(A)$ and between $\mathrm{CRH}$-stimulated AVP and ACTH ISG at $10 \mathrm{~min}(B)$. ulated ACTH and AVP concentrations. AVP did not change after oCRH in the nondominant IPS or the periphery. Basal OT also showed an intersinus gradient, from the same dominant IPS. In contrast to its effects on ACTH and AVP, CRH did not change petrosal sinus OT. Basal endogenous CRH in the petrosal sinuses and the periphery was found to be below the detection limit of the assay. After oCRH administration, exogenous oCRH levels were similar in the two petrosal sinuses.

Our previous results (4) and those of the present study show that lateralization of CRH-induced ACTH release is not limited to Cushing disease, as previously reported (1-3) but is rather a generalized phenomenon exhibited by healthy individuals. Moreover, the present data show that in response to $\mathrm{CRH}, \mathrm{AVP}$ is secreted into the same dominant petrosal sinus as is ACTH. To our knowledge, this is the first study to demonstrate a stimulatory effect of CRH on petrosal AVP concentrations in normal human subjects. Despite evidence that $\mathrm{CRH}$ stimulates plasma AVP and OT in animals (24-27), a number of studies measuring peripheral AVP have failed to demonstrate such an effect in humans (28-30). In the present study, however, CRH-induced AVP secretion was detectable only in the dominant IPS, before the dilution of pituitary effluent by the systemic circulation. Our findings support those of Oelkers and Ahmed who found high circulating AVP and hyponatremia in primary hypopituitarism (35) and Addison disease (36), respectively. This might be, to a certain extent, the result of chronic hypersecretion of CRH. It is also conceivable that other causes of inappropriate AVP secretion, such as stress, pain, malignant and nonmalignant lung disease, and central nervous system trauma and infections (37-39) may act, at least in part, through eutopic or ectopic CRH hypersecretion.

The cell body that secretes AVP in response to $\mathrm{CRH}$ is unknown. In rats, specific, high affinity $\mathrm{CRH}$ receptors have been identified by autoradiography in the median eminence (ME) and the intermediate lobe but not in the posterior lobe of the pituitary (40-44). Although $\mathrm{CRH}$ has been shown to stimulate magnocellular AVP and OT from the isolated rat neurointermediate pituitary $(45,46)$, this mechanism is not likely to pertain to humans in whom the intermediate lobe is rudimentary. However, it may explain the observed clear stimulatory effect of CRH on peripheral plasma AVP and OT in animals (24-27) and the absence of an effect in humans (28-30). AVP terminals in the ME are of parvocellular origin; however, we believe that the observed AVP elevation in the dominant petrosal sinus is predominantly of magnocellular origin, for the following reasons: The amount of parvocellular AVP is at least one order of magnitude lower than that released by magnocellular neurons (47). In agreement with this notion, endogenous CRH levels in the IPS of our subjects were below the detection limit of our assay $(<1.8 \mathrm{pmol} / \mathrm{liter})$, indicating that the amount of parvocellular AVP measurable in the IPS should also be quite small. Finally, magnocellular axons as they pass through the ME can be stimulated to release AVP from distinct swellings, known as Herring bodies, in which AVP secretory vesicles are abundant (11). Therefore, we postulate that CRH may induce predominantly magnocellular and to a smaller extent parvocellular AVP secretion, through ME and possibly as yet unidentified posterior pituitary CRH receptors, that could in turn, gain access to the anterior pituitary through both long and short portal vessels and thus modulate ACTH release.

Our data lead us to speculate that even endogenous $\mathrm{CRH}$, 
released from parvocellular nerve terminals during stress, might act directly to release AVP from the ME, an effect that could enhance CRH-mediated ACTH secretion. This could represent a novel mechanism by which endogenous CRH promotes ACTH secretion. The existence of such a mechanism implies that CRH-induced ACTH secretion might involve factors other than basal plasma cortisol levels and anterior pituitary $\mathrm{CRH}$ receptor number but also $\mathrm{CRH}$ receptor number in the ME and the releasability of AVP in response to CRH.

The existence of a basal intersinus gradient of multiple anterior pituitary hormones previously noted in Cushing disease $(48,49)$, as well as the currently noted ISG for ACTH, AVP, and OT, might be explained as an artifact of the IPS sampling technique per se. Thus, variations in the location of the two catheters at the time of collection, in the anatomy of the two petrosal sinuses, in the extent of blood flow through the intercavernous sinuses, in the amount of nonpituitary blood mixing with cavernous sinus blood, or in the relative number of corticotrophs drained by each petrosal sinus could cause differences in the amount of pituitary hormones found in the two petrosal sinuses in the basal state. While these factors associated with the IPS sampling technique might account for the small intersinus ACTH gradient observed in normal subjects during baseline conditions $(2.2 \pm 0.7)$, it seems unlikely that they could explain the sevenfold increase in the intersinus ACTH gradient after the administration of CRH. For instance, if the higher baseline ACTH concentrations seen in one petrosal sinus were merely reflecting a dominant petrosal sinus draining a greater number of pituicytes, which were nevertheless exposed to similar concentrations of hypothalamic secretagogues, one would expect a comparable degree of ACTH stimulation in response to $\mathrm{CRH}$ in both petrosal sinuses and no net change in the ACTH ISG after the administration of CRH. Therefore, we suggest that the existence of a dominant petrosal sinus with respect to ACTH secretion in normal human subjects appears to reflect a dominant side of the anterior pituitary gland itself, characterized by increased functional activity and/or responsiveness of the pituitary corticotrophs, which may be a result of greater ipsilateral AVP secretion.

There are several reasons why the basal AVP ISG did not correlate with the ACTH ISG. The stimulatory effect of increased AVP in the dominant petrosal sinus may have been neutralized by the inhibitory effect of elevated OT concentrations. Furthermore, AVP by itself is a weak ACTH secretagogue and requires $\mathrm{CRH}$ to exert a potent effect on the release of ACTH. Even though inferior petrosal sinus cannulation is regarded as a stressful procedure, endogenous $\mathrm{CRH}$ levels in both petrosal sinuses were found to be below the detection limit of our assay, probably due to the pretreatment of our subjects with fentanyl and diazepam, both of which are known to inhibit hypothalamic CRH secretion $(50,51)$. Therefore, low CRH secretion during baseline sampling and a diminished synergistic effect with AVP probably account for the absence of a correlation between the ACTH and the AVP ISG. However, the dynamics of ACTH secretion changed dramatically after administration of exogenous $\mathrm{CRH}$, especially on the dominant side of the anterior pituitary. CRH induced AVP secretion in the dominant petrosal sinus only, resulting in a threefold increase in the AVP ISG. Furthermore, increased levels of exogenously administered oCRH were then available to synergize with the increased AVP concentrations on the pu- tative dominant side. The result was secretion of ACTH predominantly into the dominant petrosal sinus, a sevenfold increase in the ACTH ISG and a highly statistically significant correlation between the AVP and the ACTH ISG.

We cannot definitively determine the etiology of lateralized AVP and OT secretion. It is conceivable that parvocellular and/or magnocellular nerve terminals are distributed in an asymmetric fashion in the ME and the posterior pituitary, and thus drain asymmetrically into the petrosal sinuses. However, while this may account for basal AVP and OT gradients, it can not explain the significant threefold increase in the AVP ISG observed after the administration of oCRH. A nonspecific effect on IPS hemodynamics caused by oCRH is also unlikely, since no change in the OT ISG was observed. Therefore, an intriguing hypothesis arises from our finding; the concept of a dominant side of the hypothalamus with respect to neurosecretory activity and responsiveness. Such a dominant side of the hypothalamus could result from increased stimulatory input from higher centers in the limbic system and/or the cortex. At present there is widespread evidence from neuroanatomical and functional studies that, in right-handed individuals, the left hemisphere is specialized for handedness, speech, and neuroimmunomodulation while the right hemisphere predominates in spatial abilities, expression of affect, and control of vital functions supporting survival (52). Recent data by Wittling et al. suggest that, in $80 \%$ of right-handed individuals, activation of the hypothalamic-pituitary-adrenal axis is controlled by the right hemisphere $(53,54)$. This is consonant with our results, since in $78 \%$ of our right-handed subjects, the right petrosal sinus was dominant, with respect to ACTH, AVP, and OT secretion.

The functional and teleologic significance of a normally occurring dominant side of the anterior pituitary gland with respect to ACTH secretion is not known. Whether it has physiological relevance during severe chronic stress and whether the nondominant half of the anterior pituitary might constitute a pool of ACTH that would be releasable under extreme conditions remains to be elucidated. Furthermore, the intriguing concept of brain lateralization with respect to neuroendocrine secretion and the possible implications on asymmetric involvement of the two hemispheres in the pathophysiology of somatic and mental illness deserve further investigation.

\section{Acknowledgments}

The authors wish to thank Drs. Greti Aguilera, Carolyn A. Bondy, Miles Harkenham, and Robert B. Page for critically reviewing the manuscript. We gratefully acknowledge Patrick D. Yao, Ruchi Puri, and James S. Lee for assistance with the radioimmunoassays.

\section{References}

1. Manni, A., R.F. Latshaw, R. Page, and R.J. Santen. 1983. Simultaneous bilateral venous sampling for adrenocorticotropin in pituitary-dependent Cushing's disease: evidence for lateralization of pituitary venous drainage. J. Clin. Endocrinol. Metab. 57:1070-1073.

2. Oldfield, E.H., G.P. Chrousos, H.M. Schulte, M. Schaaf, P.E. McKeever, A.G. Krudy, G.B. Cutler, Jr., D.L. Loriaux, and J.L. Doppman. 1985. Preoperative lateralization of ACTH-secreting pituitary microadenomas by bilateral and simultaneous inferior petrosal venous sinus sampling. N. Engl. J. Med. 312:100103.

3. Landolt, A.M., A. Valavanis, J. Girard, and A.N. Eberle. 1986. Corticotrophin-releasing factor-test used with bilateral, simultaneous inferior petrosal sinus blood-sampling for the diagnosis of pituitary-dependent Cushing's disease. Clin. Endocrinol. 25:687-696. 
4. Yanovski, J.A., G.B. Cutler, Jr., J.L. Doppman, D.L. Miller, G.P. Chrousos, E.H. Oldfield, and L.K. Nieman. 1993. The limited ability of inferior petrosal sinus sampling with corticotropin-releasing hormone to distinguish Cushing's disease from pseudo-Cushing states or normal physiology. J. Clin. Endocrinol. Metab. 77:503-509.

5. Vale, W., J. Spiess, C. Rivier, and J. Rivier. 1981. Characterization of a 41-residue hypothalamic peptide that stimulates secretion of corticotropin and $\beta$-endorphin. Science (Wash. DC). 213:1394-1397.

6. Gillies, G.E., E.A. Linton, and P.J. Lowry. 1982. Corticotropin releasing activity of the new CRF is potentiated several times by vasopressin. Nature (Lond.). 299:355-357.

7. Vale, W., J. Vaughan, M. Smith, G. Yamamoto, J. Rivier, and C. Rivier. 1983. Effects of synthetic ovine corticotropin-releasing factor, glucocorticoids, catecholamines, neurohypophysial peptides, and other substances on cultured corticotropic cells. Endocrinology. 113:1121-1131.

8. Liu, J.H., K. Muse, P. Contreras, D. Gibbs, W. Vale, J. Rivier, and S.S.C. Yen. 1983. Augmentation of ACTH-releasing activity of synthetic corticotropin releasing factor (CRF) by vasopressin in women. J. Clin. Endocrinol. Metab. 57: 1087-1089.

9. Whitnall, M.H., D. Smyth, and H. Gainer. 1987. Vasopressin coexists in half of the corticotropin-releasing factor axons present in the external zone of the median eminence in normal rats. Neuroendocrinology. 45:420-424.

10. Pretel, S., and D.T. Piekut. 1990. Coexistence of CRF peptide and oxytocin mRNA in the paraventricular nucleus. Peptides (Tarryt.). 11:621-624.

11. Holmes, M.C., F.A. Antoni, G. Aguilera, and K.J. Catt. 1986. Magnocellular axons in passage through the median eminence release vasopressin. $\mathrm{Na}$ ture (Lond.). 319:326-329.

12. Baertschi, A.J. 1980. Portal vascular route from hypophysial stalk/neural lobe to adenohypophysis. Am. J. Physiol. 239:R463-R469.

13. Bergland, R.M., and R.B. Page. 1978. Can the pituitary secrete directly to the brain? (affirmative anatomical evidence). Endocrinology. 102:1325-1338.

14. Page, R.B. 1983. Directional pituitary blood flow: a microcinephotographic study. Endocrinology. 112:157-165.

15. Antoni, F.A. 1986. Hypothalamic control of adrenocorticotropin secretion: advances since the discovery of 41-residue corticotropin-releasing factor. Endocr. Rev. 7:351-378.

16. Chiodera, P., C. Salvarani, A. Bacchi-Modena, R. Spallanzani, C. Cigarini, A. Alboni, E. Gardini, and V. Coiro. 1991. Relationship between plasma profiles of oxytocin and adrenocorticotropic hormone during suckling or breast stimulation in women. Horm. Res. (Basel). 35:119-123.

17. Amico, J.A., J.M. Johnston, and A.H. Vagnucci. 1994. Suckling-induced attenuation of plasma cortisol concentrations in postpartum lactating women. Endocr. Res. 20:79-87.

18. Legros, J.J., P. Chiodera, and E. Demey-Ponsart. 1982. Inhibitory influence of exogenous oxytocin on adrenocorticotropin secretion in normal human subjects. J. Clin. Endocrinol. Metab. 55:1035-1039.

19. Legros, J.J., P. Chiodera, V. Geenen, S. Smitz, and R. Von Frenckell. 1984. Dose-response relationship between plasma oxytocin and cortisol and adrenocorticotropin concentrations during oxytocin infusion in normal men. $J$. Clin. Endocrinol. Metab. 58:105-109.

20. Coiro, V., M. Passeri, C. Davoli, A. Bacchi-Modena, L. Bianconi, R. Volpi, and P. Chiodera. 1988. Oxytocin reduces exercise-induced ACTH and cortisol rise in man. Acta Endocrinol. 119:405-412.

21. Page, S.R., V.T.Y. Ang, R. Jackson, A. White, S.S. Nussey, and J.S. Jenkins. 1990. The effect of oxytocin infusion on adenohypophyseal function in man. Clin. Endocrinol. 32:307-313.

22. Lewis, D.A., and B.M. Sherman. 1985. Oxytocin does not influence adrenocorticotropin secretion in man. J. Clin. Endocrinol. Metab. 60:53-56.

23. Nussey, S.S., S.R. Page, V.T.Y. Ang, J.S. Jenkins, and A. White. 1988. The effect of oxytocin infusion on adenohypophysial and adrenal cortical responses to insulin-induced hypoglycaemia. Clin. Endocrinol. 29:257-264.

24. Raff, H., M.M. Skelton, D.C. Merrill, and A.W. Cowley, Jr. 1986. Vasopressin responses to corticotropin releasing factor and hyperosmolality in conscious dogs. Am. J. Physiol. 251:R1235-R1239.

25. Klingbeil, C.K., L.C. Keil, D. Chang, and I.A. Reid. 1988. Effects of $\mathrm{CRF}$ and ANG II on ACTH and vasopressin release in conscious dogs. Am. J. Physiol. 255:E46-E53.

26. Carlson, D.E., A.M. Nabavian, L.M. Brown, and D.S. Gann. 1993. Microinjections of corticotropin-releasing hormone into the medial parabrachial nucleus facilitate plasma vasopressin in cats. Ann. NY Acad. Sci. 689:480-483.

27. Bruhn, T.O., S.W. Sutton, P.M. Plotsky, and W.W. Vale. 1986. Central administration of corticotropin-releasing factor modulates oxytocin secretion in the rat. Endocrinology. 119:1558-1563.

28. Conaglen, J.V., R.A. Donald, E.A. Espiner, J.H. Livesey, and M.G. Nicholls. 1984. The effect of ovine corticotropin-releasing factor on catecholamine, vasopressin, and aldosterone secretion in normal man. J. Clin. Endocrinol. Metab. 58:463-466.

29. Rittmaster, R.S., G.B. Cutler, Jr., D.O. Sobel, D.S. Goldstein, M.C.S. Koppelman, D.L. Loriaux, and G.P. Chrousos. 1985. Morphine inhibits the pi- tuitary-adrenal response to ovine corticotropin-releasing hormone in normal subjects. J. Clin. Endocrinol. Metab. 60:891-895.

30. Milsom, S.R., J.V. Conaglen, R.A. Donald, E.A. Espiner, M.G. Nicholls, and J.H. Livesey. 1985. Augmentation of the response to CRF in man: relative contributions of endogenous angiotensin and vasopressin. Clin. Endocrinol. 22:623-628.

31. Nussey, S.S., S.R. Page, D.B. Peterson, J. Byrne, S.R. Crosby, A. White, V.T.Y. Ang, R. Jackson, and J.S. Jenkins. 1991. Corticotrophin releasing hormone $\left(\mathrm{CRH}_{1-41}\right)$ stimulates the secretion of adrenocorticotrophin, vasopressin and oxytocin but not adrenocorticotrophin precursors: evidence from petrosal sinus sampling in man. Clin. Endocrinol. 34:51-56.

32. Miller, D.L., and J.L. Doppman. 1991. Petrosal sinus sampling: technique and rationale. Radiology. 178:37-47.

33. Chrousos, G.P., H.M. Schulte, E.H. Oldfield, P.W. Gold, G.B. Cutler, $\mathrm{Jr}$, and D.L. Loriaux. 1984. The corticotropin-releasing factor stimulation test: an aid in the evaluation of patients with Cushing's syndrome. N. Engl. J. Med. 310:622-626.

34. Schurmeyer, T.H., P.W. Gold, W.T. Gallucci, T.P. Tomai, G.B. Cutler, Jr., D.L. Loriaux, and G.P. Chrousos. 1985. Effects and pharmacokinetic properties of the rat/human corticotropin-releasing factor in rhesus monkeys. Endocrinology. 117:300-306.

35. Oelkers, W. 1989. Hyponatremia and inappropriate secretion of vasopressin (antidiuretic hormone) in patients with hypopituitarism. N. Engl. J. Med. 321:492-496.

36. Ahmed, A.B.J., B.C. George, C. Gonzalez-Auvert, and J.F. Dingman. 1967. Increased plasma arginine vasopressin in clinical adrenocortical insufficiency and its inhibition by glucosteroids. J. Clin. Invest. 46:111-123.

37. Bartter, F.C., and W.B. Schwartz. 1967. The syndrome of inappropriate secretion of antidiuretic hormone. Am. J. Med. 42:790-806.

38. Moses, A.M., M. Miller, and D.H.P. Streeten. 1976. Pathophysiologic and pharmacologic alterations in the release and action of ADH. Metabolism. 25:697-721.

39. Clich, D. 1982. Syndrome of inappropriate antidiuretic hormone secretion associated with stress. Lancet. i:1131-1132.

40. De Souza, E.B., M.H. Perrin, J. Rivier, W.W. Vale, and M.J. Kuhar. 1984. Corticotropin-releasing factor receptors in the rat pituitary gland: autoradiographic localization. Brain Res. 296:202-207.

41. De Souza, E.B., M.H. Perrin, P.J. Whitehouse, J. Rivier, W. Vale, and M.J. Kuhar. 1985. Corticotropin-releasing factor receptors in human pituitary gland: autoradiographic localization. Neuroendocrinology. 40:419-422.

42. De Souza, E.B., M.H. Perrin, T.R. Insel, J. Rivier, W.W. Vale, and M.J. Kuhar. 1984. Corticotropin-releasing factor receptors in rat forebrain: autoradiographic identification. Science (Wash. DC). 224:1449-1451.

43. Millan, M.A., A.-B. Abou Samra, P.C. Wynn, K.J. Catt, and G. Aguilera. 1987. Receptors and actions of corticotropin-releasing hormone in the primate pituitary gland. J. Clin. Endocrinol. Metab. 64:1036-1041.

44. Grigoriadis, D.E., and E.B. De Souza. 1989. Corticotropin-releasing factor (CRF) receptors in intermediate lobe of the pituitary: biochemical characterization and autoradiographic localization. Peptides (Tarryt.). 10:179-188.

45. AlZein, M., L. Jeandel, B. Lutz-Bucher, and B. Koch. 1984. Evidence that CRF stimulates vasopressin secretion from isolated neurointermediate pituitary. Neuroendocrinol. Lett. 6:151-155.

46. Bondy, C.A., and H. Gainer. 1989. Corticotropin-releasing hormone stimulates neurohypophysial hormone release through an interaction with the intermediate lobe of the pituitary. J. Neuroendocrinol. 1:5-8.

47. Makara, G.B. 1993. Denervation of the rat posterior pituitary gland: validation of a stereotaxic method. J. Neuroendocrinol. 5:335-340.

48. Crock, P.A., R.G. Pestell, A.J. Galenti, E.J. Gilford, J.K. Henderson, J.D. Best, and F.P. Alford. 1988. Multiple pituitary hormone gradients from inferior petrosal sinus sampling in Cushing's disease. Acta Endocrinol. 119:75-80.

49. Zovickian, J., E.H. Oldfield, J.L. Doppman, G.B. Cutler, Jr., and D.L. Loriaux. 1988. Usefulness of inferior petrosal sinus venous endocrine markers in Cushing's disease. J. Neurosurg. 68:205-210.

50. Tsagarakis, S., P. Navara, L.H. Rees, M. Besser, and A. Grossman. 1989 Morphine directly modulates the release of stimulated corticotrophin-releasing factor-41 from rat hypothalamus in vitro. Endocrinology. 124:2330-2335.

51. Kalogeras, K.T., A.E. Calogero, T. Kuribayiashi, I. Khan, W.T. Gallucci, M.A. Kling, G.P. Chrousos, and P.W. Gold. 1990. In vitro and in vivo effects of the triazolobenzodiazepine alprazolam on hypothalamic-pituitary-adrenal function: pharmacological and clinical implications. J. Clin. Endocrinol. Metab. 70:1462-1471.

52. Springer, S.P., and G. Deutsch. 1993. Left Brain, Right Brain. W.H. Freeman and Co., New York. 368 pp.

53. Wittling, W., and M. Pfluger. 1990. Neuroendocrine hemisphere asymmetries: salivary cortisol secretion during lateralized viewing of emotion-related and neutral films. Brain Cognit. 14:243-265.

54. Wittling, W., and E. Schweiger. 1993. Neuroendocrine brain asymmetry and physical complaints. Neuropsychologia. 31:591-608. 